\title{
Global learning on carbon capture and storage: A call for strong international cooperation on CCS demonstration
}

\author{
Heleen de Coninck ${ }^{\mathrm{a}, \mathrm{b}, *}$, Jennie C. Stephens ${ }^{\mathrm{c}, \mathrm{d}}$, Bert Metz ${ }^{\mathrm{e}}$ \\ ${ }^{a}$ Energy research Centre of the Netherlands (ECN), Unit Policy Studies, Amsterdam, The Netherlands \\ ${ }^{\mathrm{b}}$ Institute for Environmental Studies, VU University of Amsterdam, The Netherlands \\ ${ }^{\mathrm{c}}$ Energy Technology Innovation Policy, Harvard Kennedy School, Cambridge, MA, USA \\ ${ }^{\mathrm{d}}$ Department of International Development, Community and Environment, Clark University, Worcester, MA, USA \\ e European Climate Foundation, The Hague, The Netherlands
}

\section{A R T I C L E I N F O}

\section{Article history:}

Received 20 January 2009

Accepted 21 January 2009

Available online 12 March 2009

\section{Keywords:}

CCS

Climate policy

International cooperation

\begin{abstract}
A B S T R A C T
Closing the gap between carbon dioxide capture and storage (CCS) rhetoric and technical progress is critically important to global climate mitigation efforts. Developing strong international cooperation on CCS demonstration with global coordination, transparency, cost-sharing and communication as guiding principles would facilitate efficient and cost-effective collaborative global learning on CCS, would allow for improved understanding of the global capacity and applicability of CCS, and would strengthen global trust, awareness and public confidence in the technology.
\end{abstract}

(c) 2009 Elsevier Ltd. All rights reserved.

\section{Introduction}

Carbon dioxide capture and storage (CCS) technology is increasingly recognized as having critical potential to mitigate climate change (IPCC, 2005; IEA, 2008). CCS is the only technology that reduces carbon emissions from coal-fired power plants, and as such is essential as coal is at present the predominant fuel for electricity and responsible for no less than $40 \%$ of global $\mathrm{CO}_{2}$ emissions. About $100 \mathrm{GW}$ of additional coal-fired power capacity is currently built every year, and the use of coal is projected to increase in the decades to come (IEA, 2008). It has been suggested that confidence in CCS could be a pre-requisite for a global agreement on large-scale $\mathrm{CO}_{2}$ emissions reductions (Gibbins and Chalmers, 2008). CCS technology can also be considered in combination with renewable energy; when CCS is applied to biomass-fired power plants, it can provide carbon-negative electricity generation that directly lowers carbon dioxide concentrations in the atmosphere (IPCC, 2005).

Despite growing international interest in CCS, no fully integrated power plants with CCS have yet been built at scale although the need for CCS demonstration projects is widely acknowledged to be urgent (see e.g., G8, 2008). A large gap has emerged between the political discourse surrounding the promise of the technology and the scale of technological learning that still must occur before the technology can contribute to meaningful

\footnotetext{
* Corresponding author at: Energy research Centre of the Netherlands (ECN), Unit Policy Studies, Amsterdam, The Netherlands.

E-mail address: deconinck@ecn.nl (H. de Coninck).
}

carbon dioxide reductions. To minimize this gap, we are calling for strong international cooperation that can provide global learning about CCS by coordinating and financing CCS demonstration efforts throughout the world. We argue that enhanced international cooperation for CCS demonstration is the optimal, and perhaps the only way to achieve sufficient learning in time.

\section{Status of CCS}

CCS is not a single technology but consists of sets of technological components associated with capturing, transporting and storing $\mathrm{CO}_{2}$ deep underground. While many of the individual components of a CCS system have already been used in other industrial applications, the technological maturity of different CCS components varies (see Fig. 1).

Progress on the technological maturity of the various components has been slow over the past five years; only in oxyfuel combustion there has been significant recent progress with the opening of a $\mathrm{CO}_{2}$ capture demonstration plant with aquifer storage near Berlin, Germany (and concrete plans to expand the $30 \mathrm{MW}$ plant to $300 \mathrm{MW}$ ). Despite limited progress and variation in technological readiness among the different components, there is widespread optimism about the technical feasibility of all components of CCS and about the integration of the components. The critical obstacle at this point is that CCS in the power sector has not yet been demonstrated at scale, therefore technological risks, which enhance the already significant cost barrier, are a clear near-term barrier to implementation. 


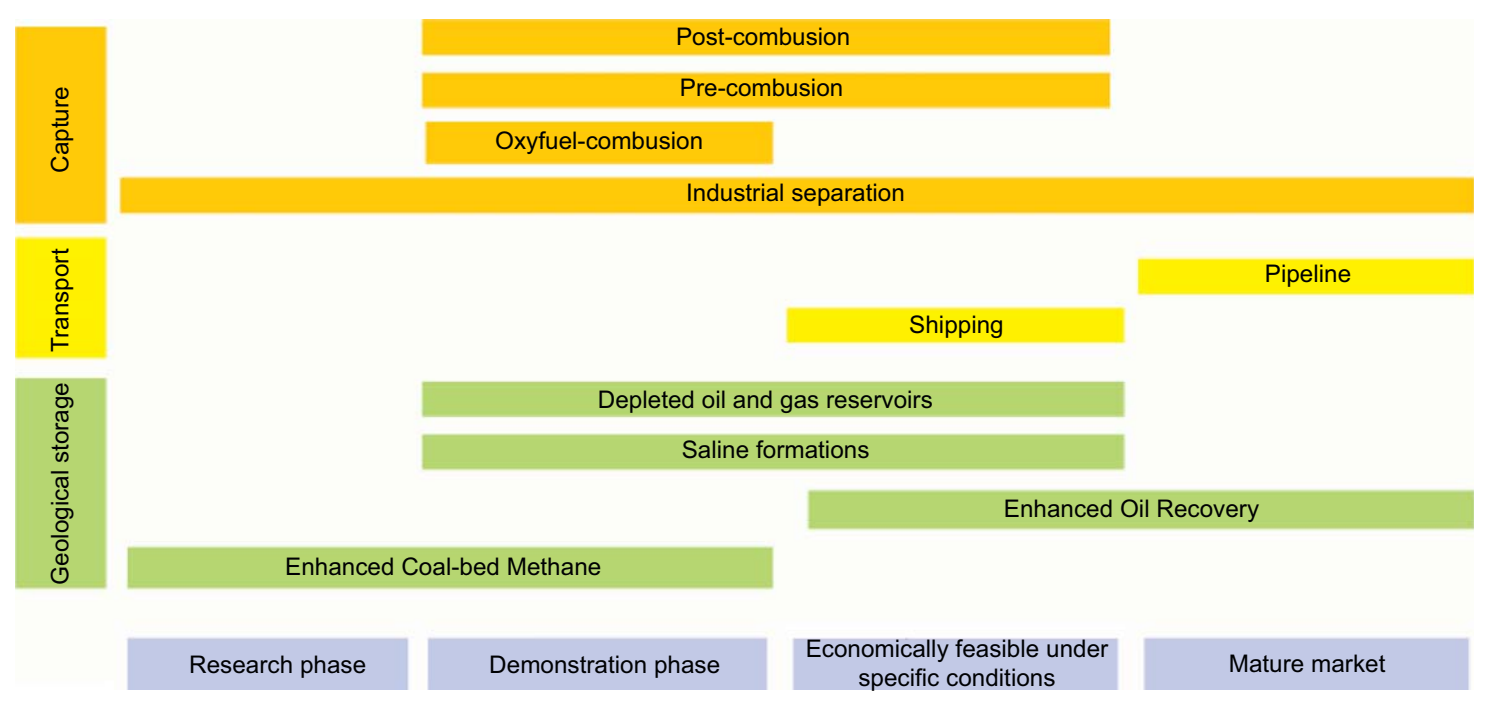

Fig. 1. Stages of maturity of CCS capture, transport and storage components (after IPCC, 2005).

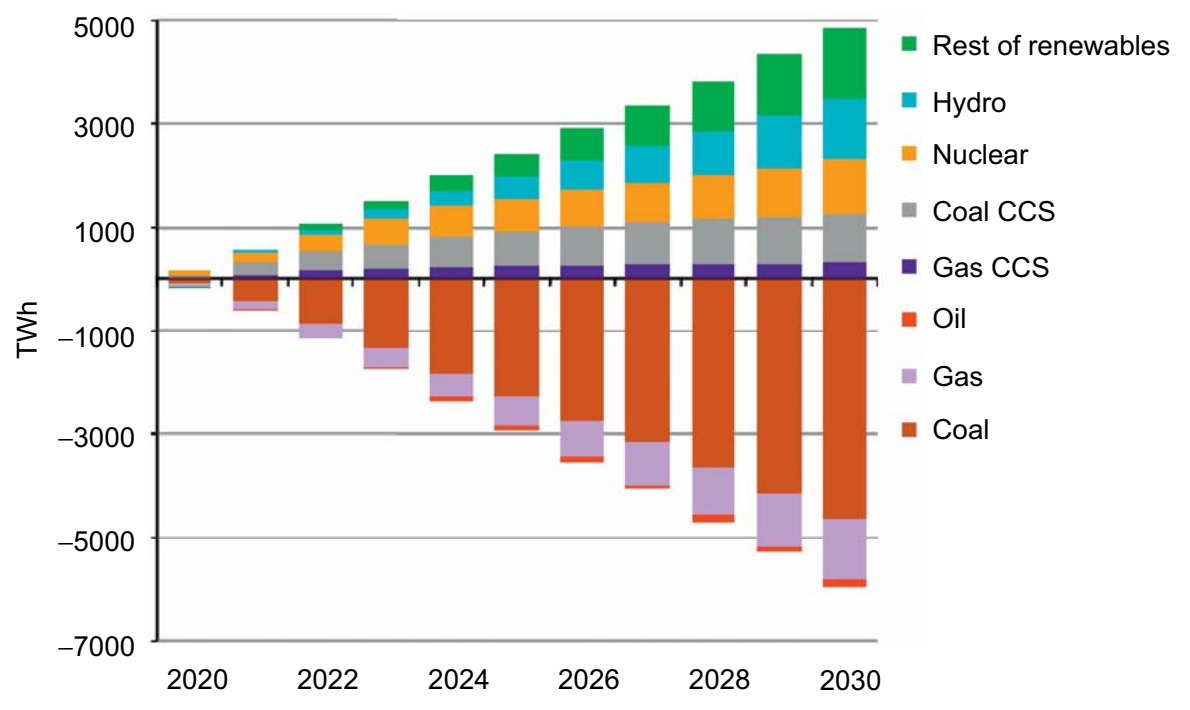

Fig. 2. Change in world electricity generation in the 450 vs. the 550 Policy Scenario, 2020-2030 (IEA WEO, 2008).

A lack of funding for the large-scale demonstration of technologies is a well-recognized problem in technology innovation. After a successful R\&D phase, public funding is often reduced, while private funding for application of the technology is still seen as uneconomical or too risky. The cash flow for the new technology dries up, and the ensuing "valley of death" looms (Murphy and Edwards, 2003). This pattern of difficulty at the demonstration phase can be identified in many technologies, but is particularly pronounced in large-scale, capital intensive technologies such as CCS.

Most global emission projections are currently suggesting that large-scale implementation of CCS is required to achieve deep reductions in emissions within the next few decades. The IEA World Energy Outlook (2008), for example, shows that significant CCS deployment is needed from 2020 to 2030 to achieve a $450 \mathrm{ppmv}$ instead of a $550 \mathrm{ppmv}$ stabilization scenario (Fig. 2). These projections highlight the urgent need to accelerate CCS demonstration so significant learning is made before 2020 .
Given the prominent role that CCS is now taking in considering global attempts to attain climate mitigation goals in terms of the deep reductions needed in the 2020-2030 timeframe (IPCC, 2007), it is essential that CCS does not fall into this "valley of death" trap, that the process of technological learning is accelerated, and that costs are reduced. Fortunately, it is widely acknowledged that demonstration of various different configurations of a full CCS system is urgently needed. Various countries, notably Canada, Norway, the European Union, the United States and Australia plan full-scale CCS demonstrations in a variety of applications. The European Union plans to use part of its Emissions Trading Auction revenues for CCS, and the US Senate Democrats recently proposed US\$ 2.4 billion for CCS in a fiscal recovery package. We argue, however, that through such a scattered demonstration approach, opportunities to minimize the gap between the optimistic CCS rhetoric and the practical needs of learning-by-doing may be missed. If global learning on CCS is to be achieved, international project coordination and even cost-sharing will be crucial. 


\section{Existing international technology initiatives}

To explain why we are calling for a new international initiative focused on CCS demonstration, we review the effectiveness of the current international CCS-related initiatives and processes: the United Nations Framework Convention on Climate Change (UNFCCC), the Carbon Sequestration Leadership Forum (CSLF), the G8, the International Energy Administration (IEA) and its Implementing Agreements and the Asian Pacific Partnership for Clean Development and Climate (APP). We explore the capacity of these existing organizations to enable internationally coordinated CCS demonstration. We also discuss the recent plans of the Australian government to set up a "Global CCS Institute".

Firstly, the UNFCCC incorporates CCS technology development in different contexts, including whether and how CCS could be included in the Clean Development Mechanism (CDM). Discussions on CCS and the CDM have been suffering from considerable controversies (de Coninck, 2008) and recent results of the UNFCCC 14th Conference of the Parties (COP-14) meeting in Poznan, Poland are not encouraging for short-term incentives for advancing CCS in developing countries. Regardless, if CCS would be allowed in the CDM, prices are unlikely to be high enough to enable CCS in the power sector. ${ }^{1}$

The CSLF was founded in 2003 on the initiative of the United States. Its charter shows that it aims to provide knowledge sharing and coordination on CCS. The CSLF has brought together policymakers of the 22 member countries, including several emerging economies, has provided some useful guidance on technical issues but has failed to involve a broad array of stakeholders and provide what CCS needs mostglobal learning in full-scale demonstrations. It is unclear how the organization will be continued by the new US Administration, but its current structure does not enable CCS demonstrations.

The G8 has called for 20 CCS demonstrations by 2010 (G8, 2008). It has also invited the International Energy Agency to cooperate with the CSLF on CCS, which resulted in a recently published report on CCS (IEA, 2008). The IEA also features two Implementing Agreements that cover CCS: the IEA Clean Coal Centre and the IEA Greenhouse Gas R\&D Centre. These initiatives are cost-sharing agreements, but their budgets are currently insufficient to help CCS demonstration.

In 2005, the United States and six other countries initiated the Asia-Pacific Partnership on Clean Development and Climate, which aims to "accelerate the development and deployment of clean energy technologies". It is organized in eight task forces, including cleaner use of fossil fuel, which has CCS as a one of its priority thematic areas. Although some initiatives in the field of research and capacity building have been realized, there has been no full-scale demonstration of CCS under the APP and current budgets are insufficient.

Lastly, the Australian Government recently launched a Global CCS Institute, with the aim of facilitating CCS demonstrations worldwide. Still in an early stage of development, it is unclear how this new entity will achieve its goals of supporting CCS demonstration projects. It is not yet clear whether its policies, approaches and supporting mechanisms will be able to maximize global learning through coordinated CCS demonstration projects, but in principle the initiative could provide the coordinated project planning that we are calling for.

\footnotetext{
${ }^{1}$ Studies show that CCS in other sectors, notably gas processing, would likely be enabled.
}

\section{Justification for international coordination for CCS demonstration}

Numerous benefits of international cooperation in energy technology development have been identified in previous studies (PCAST, 1999; NCEP, 2004). Based on such studies, we identify four arguments for far-reaching international cooperation on CCS demonstration: (1) accelerating learning, (2) globalizing learning, especially in countries that might not independently invest in the technology, (3) expanding social awareness of and discourse about the acceptability of CCS and (4) ensuring consistent, safe implementation of $\mathrm{CO}_{2}$ storage. For $\mathrm{CCS}$, these benefits can only be maximized through the creation of an international program or organization that coordinates the planning, implementation and learning from CCS demonstration projects throughout the world.

\subsection{Accelerating learning}

International coordination of CCS demonstration efforts, if designed and managed well, has potential for accelerating learning and large cost reductions through multiple parallel approaches and efficiency in planning a diversity of projects. Through international coordination, demonstration projects could be designed to maximize and accelerate technological learning by integrating different individual components of a complete CCS system, and enabling transparency of information and data that would otherwise remain hidden in national demonstration programs. Coordination of demonstration of all three types of capture technology could be enabled, allowing for more informed decision-making on the best capture technology in different contexts. Similarly coordination of $\mathrm{CO}_{2}$ storage in different types of geological formations will accelerate learning on appropriate storage considerations. Improved and methodologically consistent regional capacity estimates could emerge cost-effectively if CCS demonstration projects in different parts of the world were internationally coordinated and planned.

\subsection{Globalizing learning}

CCS is a technology with large global potential but the awareness, knowledge, storage potential and interest differs greatly between countries. The technical potential and appropriateness for CCS in many places of the world is not well characterized, and those currently interested and invested in CCS are concentrated in few regions of the world. International coordination of technology development efforts, therefore, is essential to the advancement of CCS. Simultaneous demonstration of CCS in various different political, social and geological contexts, in both developed and developing countries, would provide synergistic learning opportunities. Internationally coordinated CCS demonstration projects could integrate feedback from individual projects in different countries and contexts and thus globalize the learning process.

International coordination would also inform the potential applicability of CCS in large emerging economies with a current heavy reliance on coal, and would identify whether they can rely on CCS to reduce their future emissions. Improving understanding of the potential for CCS deployment in India, for instance, is critical for considering global climate mitigation strategies. India's geological storage capacity appears limited (Holloway et al., 2008), its government shows minimal interest in CCS demonstration or policy (Kapila and Haszeldine, 2008; Shackley and Verma, 2008) and the characteristics of its coal require more advanced capture technology, making CCS deployment unlikely (Chikkatur and Sagar, 2008). Learning from a globally coordinated CCS 
demonstration effort could change these current general perceptions about the future of CCS in India. In addition, while the call for "developed-country-first" demonstration of CCS has been made (G8, 2008; Gibbins and Chalmers, 2008), China, South Africa and Brazil have shown considerable interest in applying CCS, but these countries lack the human, institutional and financial capacity to implement it. If a common financial instrument could be initiated under a strong international CCS demonstration, demonstrations in these countries could be funded by industrialized countries through a cost-sharing approach.

\subsection{Expanding social awareness of and discourse about the acceptability of CCS}

An additional benefit of internationally coordinated CCS demonstration includes the potential to enhance global awareness of and public discourse about this emerging energy technology with potential for considerable controversy. A dedicated and strong international cooperation on CCS demonstration indicates to the people of the world both a degree of technical legitimacy and a high level of potential value of CCS in confronting climate change. An internationally inclusive approach to CCS demonstration could be critical to enhancing public confidence and trust in the technology. Public acceptance is a precondition for widespread deployment of CCS, and building trust and public acceptance through international coordination could minimize concerns of CCS being a technology developed in wealthy developed countries that is then imposed on other countries. International sharing of successful experiences involving local stakeholders and of strategies to gain public acceptance would be an additional benefit.

\subsection{Ensuring consistency in safety and integrity of CCS projects}

Strong international cooperation for CCS demonstration projects can be designed to ensure consistency in safety and integrity of specific projects by exchanging knowledge and experience on (1) site characterization, (2) monitoring and remediation techniques and (3) the legal and regulatory frameworks. Consistency in monitoring, evaluation and verification of all steps in the complex CCS process will also facilitate comparative analysis of different projects, and will provide internationally operating companies with comparable legal frameworks, which would lower transaction costs considerably.

\section{Guiding principles for CCS demonstration}

Based on the various current needs for advancement of CCS technology, we define four principles that should guide the tasks of the strong international cooperation for CCS demonstration:

- Global coordination: the initiative should enable a variety of CCS technologies to be demonstrated in various contexts and countries.

- Transparency: the initiative should ensure open information availability, address intellectual property issues and exchange between countries to promote broad global efficient learning on CCS.

- Cost-sharing: the initiative should set up a cost-sharing structure that pools global demonstration funds and reallocates them efficiently to allow for fast access of emerging economies to CCS technology and demonstrations.

- Communication: the initiative should design mechanisms to support demonstration projects that engage broad and different types of stakeholders and that incorporate education and outreach efforts. Open and effective communication with stakeholders, the media and the general public should be integral, and the cooperation should heed principles of risk communication, and support an open dialogue on CCS with all involved.

In addition to these factors, the total number of CCS demonstration plants to be implemented in the next decade is critical and related to the overall budget. Several organizations have recently called for 20-30 demonstration plants by 2015 (Pew 2007; IEA, 2008). This number would correspond roughly to a budget of US\$ 10-20 billion-a considerable amount, but not unprecedented in the history of technological cooperation agreements. For example, the ITER nuclear fusion experiment explained below has a US\$ 12 billion budget for one demonstration plant. Contrary to nuclear fusion, CCS is a technology with considerable private sector interest, particularly from equipment suppliers or storage services providers, which could add to public funding. Other factors to be considered in CCS demonstration initiatives include the diversity of stakeholders or sectors involved in the projects, and linkage to the emerging global climate change regime.

\section{Conclusions}

The call for CCS demonstration projects has been made by many throughout the past few years, and several international organizations and national programs around the world are working on proposed CCS demonstration projects that are in various stages of planning and implementation. Although we applaud these dispersed efforts, these initiatives are showing signs of institutional fragmentation, and we question their adequacy, timeliness and mechanisms to effectively advance learning on CCS. Given the urgency of advancing efforts to timely mitigate climate change, we are calling for strong international cooperation for CCS demonstration projects that would follow guiding principles of sound coordination, transparency, costsharing and communication. Until these principles are embedded into existing or new initiatives, the desperately needed accelerated global learning on CCS will likely be missed.

The structure of a strong international cooperation could be modeled on other large-scale international technological demonstration projects where governments collaborate to advance a technology, for example the ITER fusion reactor project, which is supported by 7 countries and designed to demonstrate the scientific and technical feasibility of a full-scale fusion power reactor. Although we recognize that the cost-sharing nature of such an agreement might raise resistance with countries that contribute large sums of money, we call upon the governments involved to overcome their hesitations. Not only would countries involved have a determining say on how the money is spent, also the benefits of deep cooperation in addressing climate change and enabling global learning on CCS greatly exceed the costs.

The Australian government has assumed an ambitious leadership role in promoting CCS demonstration by launching the Global CCS Institute, which has been welcomed by many countries, including several EU Member States. As the world waits to see how the new Obama administration will prioritize climate change initiatives, it is clear that if the United States decides to contribute substantial funds to this new Global CCS Institute, the legitimacy and likely impact of this Australian initiative could be strengthened considerably. Whether strong international cooperation on CCS demonstration would take the form of a new international organization, would enhance the Global CCS Institute, or whether it would constitute a restructuring of the CSLF may not be the most important question. Rather, the critical question is whether 
such an effort would follow guiding principles of global coordination, transparency, cost-sharing and sound communication. If these principles can be incorporated, the urgent challenge of improving understanding of CCS potential could be met.

\section{References}

Chikkatur, A., Sagar, A., 2008. Carbon Mitigation in the Indian Coal-Power Sector: Options and Recommendations. 9th International Conference on Greenhouse Gas Control Technologies. Elsevier, Washington DC.

de Coninck, H., 2008. Trojan horse or horn of plenty? Reflections on allowing CCS in the CDM. Energy Policy 36 (3), 929-936.

G8, 2008. Joint Statement by G8 Energy Ministers. Aomori, Japan. Released June 8, 2008.

Gibbins, J., Chalmers, H., 2008. Preparing for global rollout: a 'developed country first' demonstration programme for rapid CCS deployment. Energy Policy 36 (2), 501-507.

Holloway, S., Garg, A., et al., 2008. A Regional Assessment of the Potential for $\mathrm{CO}_{2}$ Storage in the Indian Subcontinent. IEA Greenhouse Gas R\&D Programme, Cheltenham, UK.

IEA, 2008. $\mathrm{CO}_{2}$ Capture and Storage-A Key Carbon Abatement Option. International Energy Agency.
IEA WEO, 2008. World Energy Outlook 2008. International Energy Agency, Paris, France.

IPCC, 2005. IPCC Special Report on Carbon Dioxide Capture and Storage. Prepared by Working Group III of the Intergovernmental Panel on Climate Change. Cambridge University Press, Cambridge, United Kingdom and New York, NY, USA, 442 pp.

IPCC, 2007. Climate Change Mitigation. Working Group III's Contribution to the Fourth Assessment Report of the Intergovernmental Panel on Climate Change. Cambridge University Press, Cambridge, UK.

Kapila, R.V., Haszeldine, R.S., 2008. Opportunities in India for Carbon Capture and Storage as a Form of Climate Change Mitigation. 9th International Conference on Greenhouse Gas Control Technology. Elsevier, Washington DC.

Murphy, Edwards, 2003. Bridging the Valley of Death: Transitioning from Public to Private Finance, NREL NREL/MP-720-34036: Golden, CO.

NCEP, 2004. Ending the Energy Stalemate, A Bipartisan Strategy to Meet America's Energy Challenges. National Commission on Energy Policy.

PCAST, 1999. Powerful Partnerships: The Federal Role in International Cooperation on Energy Innovation, President's Committee of Advisors on Science and Technology.

Pew, 2007. A Program to Accelerate the Deployment of $\mathrm{CO}_{2}$ Capture and Storage. Coal Initiative Series. Pew Center on Global Climate Change, Washington, DC.

Shackley, S., Verma, P., 2008. Tackling $\mathrm{CO}_{2}$ reduction in India through use of $\mathrm{CO}_{2}$ capture and storage (CCS): prospects and challenges. Energy Policy 36 (9), 3554-3561. 